\title{
Delayed Diagnosis of a Testicular Mass During COVID-19 Pandemic in Lombardy: A Case Report
}

This article was published in the following Dove Press journal:

Research and Reports in Urology

\author{
Miriam Cieri ${ }^{\prime}$ \\ Roberto Contieri ${ }^{2,3}$ \\ Camilla De Carlo',3 \\ Giovanni Lughezzani ${ }^{2,3}$ \\ Davide Maffei ${ }^{2,3}$ \\ Piergiuseppe Colombo (D) \\ 'Department of Pathology, Humanitas \\ Clinical and Research Center - IRCCS, \\ Milan, Italy; ${ }^{2}$ Department of Urology, \\ Humanitas Clinical and Research \\ Center - IRCCS, Milan, Italy; \\ ${ }^{3}$ Department of Biomedical Sciences, \\ Humanitas University, Milan, Italy
}

\begin{abstract}
Signs and symptoms associated with testicular and paratesticular structures should not be underestimated because they may hide diseases requiring immediate evaluation and treatment, such as germline tumors or sarcomas, with the latter histotypes being more common among elderly patients. Unfortunately, the COVID-19 pandemic in Italy has led to a diagnostic delay of several malignancies and the impact of this delay has likely been underestimated. Paratesticular leiomyosarcoma represents a very rare subtype of sarcoma. Here we describe a 57-year-old man who presented to the emergency department with dyspnea and a voluminous mass in the right paratesticular region. At the appearance of the scrotal mass 9 months prior, he had refused to undergo a urological evaluation due to fear of contracting COVID-19. We present this case for its histological rarity and to document a case of diagnostic and therapeutic delay during the pandemic in Lombardy.
\end{abstract}

Keywords: COVID-19, leiomyosarcoma, mass of the testis, diagnostic delay, pandemic

\section{Introduction}

Malignant mesenchymal tumors of genitourinary tract represent approximately $2 \%$ of the soft tissue sarcomas. ${ }^{1}$ The most common site of origin is paratesticular, followed by prostate/seminal vesicles, kidney, bladder, and penis, with more than $75 \%$ arising from the spermatic cord. ${ }^{2}$

Among them, the most frequent types are paratesticular liposarcoma (20-56\%), followed by leiomyosarcoma (19-32\%) and rhabdomyosarcoma (11-24\%).

The mainstay approach of deep soft tissue masses is a core needle biopsy, as both surgical and medical treatments rely on a histological diagnosis. ${ }^{3,4}$

Radical orchiectomy with wide local excision is the recommended treatment: early recognition and adequate local resection provide the best chance of eradicating this disease and it is critical for prognosis. ${ }^{5}$

Here, we report the clinical course of paratesticular leiomyosarcoma (LMS) in a 57-year-old man whose urological referral was delayed due to COVID-19 pandemic. As a consequence, the patient underwent radical right orchiectomy after almost 1 year since symptom onset.

\section{Case}

Following the COVID-19 pandemic in Lombardy, a 57-year-old male presented to the Emergency Room in October 2020 with fever and palpitations, associated with dyspnea and asthenia. ECG and chest X-ray were performed showing atrial fibrillation and several cannonball opacities with a maximum diameter of $10 \mathrm{~cm}$. Collaterally, he
Correspondence: Piergiuseppe Colombo Department of Pathology, Humanitas Clinical and Research Center - IRCCS, Via Manzoni 56, Rozzano, Milan CAP 20089, Italy

Email piergiuseppe.colombo@humanitas.it
Research and Reports in Urology 2021:13 4I-44

41

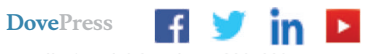

(c) (i) (5) 2021 Cieri et al. This work is published and licensed by Dove Medical Press Limited. The full terms of this license are available at https://www.dovepress.com/terms.php cc) you hereby accept the Terms. Non-commercial uses of the work are permitted without any further permission from Dove Medical Press Limited, provided the work is properly attributed. For permission for commercial use of this work, please see paragraphs 4.2 and 5 of our Terms (https://www.dovepress.com/terms.php). 
referred discomfort in the right testis since 9 months prior that had been treated by his general practitioner with antibiotics. Despite worsening of local symptoms, he also referred to have forgone any further investigation for fear of contracting COVID-19. Medical history includes mumpsinduced orchitis 35 years before. At presentation, physical examination revealed a voluminous scrotal mass, $15-\mathrm{cm}$ in diameter, solid and hyper-vascularized at US. CRP was $169 \mathrm{mg} / \mathrm{L}, \mathrm{LDH}$ was $295 \mathrm{U} / \mathrm{L}, \beta-\mathrm{HCG}$ was $1.3 \mathrm{U} / \mathrm{L}$, and $\alpha-$ FP was $2 \mathrm{ng} / \mathrm{mL}$. Total body CT-scan confirmed the presence of a testicular mass. Additionally, a $4.4 \mathrm{~cm}$ nodule in the spermatic cord and multiple bilateral pulmonary lesions (Figure 1) were observed; no lymphadenopathy was present. Due to the progressive enlargement of the lesion and worsening of symptoms, the patient underwent CT-guided pulmonary core biopsy (which confirmed metastatic disease) and concomitant radical orchiectomy with no post-operative complications.

Grossly, the tumor was a well-defined mass circumscribed by fat tissue, with a fascicular greyish white cut surface. Some areas reminiscent of necrosis were also noted.

Histopathological examination revealed a pleomorphic spindle-shaped cells mesenchymal neoplasm, with high mitotic rate and immunophenotypic profile (smooth muscle actin+, desmin+, h-caldesmon+, MDM2-), originating from paratesticular tunica (Figure 2); no amplification of MDM2 gene was observed at fluorescent in situ hybridization (FISH), excluding a dedifferentiated liposarcoma, and features were consistent with a high-grade pleomorphic leiomyosarcoma. Adjacent to the tumor, minimal residual atrophic testis parenchyma was also observed. At a post-operatory control, due to concomitant hypertension and atrial fibrillation with enlargement of left atrial chamber, a multidisciplinary sarcoma Board confirmed indication for gemcitabine-based chemotherapy.

\section{Discussion}

Differential diagnosis of asymptomatic scrotal enlargement varies widely from benign conditions, such as hydrocele and inguinoscrotal hernia, to other rarer tumors including benign leiomyoma, adenomatoid tumor, pseudotumors, fibromatosis and testicular malignancy. ${ }^{6}$

Malignant paratesticular soft tissue tumors are remarkably rare entities with liposarcoma being the most frequent subtype, followed by rhabdomyosarcoma and leiomyosarcoma. ${ }^{1}$

LMS can arise from any tissue containing smooth muscle, although the real precursor cell of these kind of

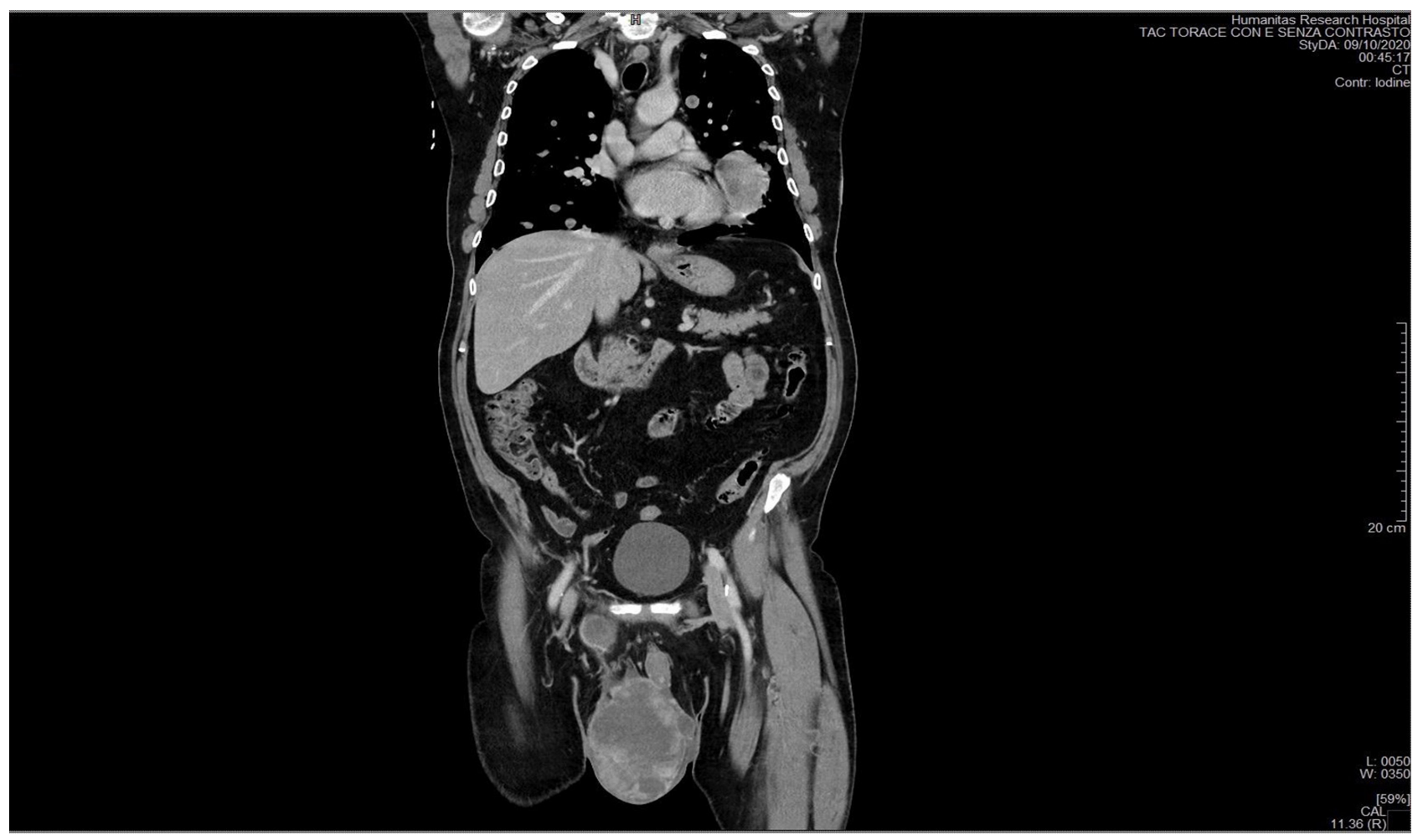

Figure I Chest computerized tomography showing the testicular mass, a second $4.4 \mathrm{~cm}$ nodule in the spermatic cord, and multiple solid lesions in both lungs, $15 \mathrm{~cm}$ in maximum diameter. 

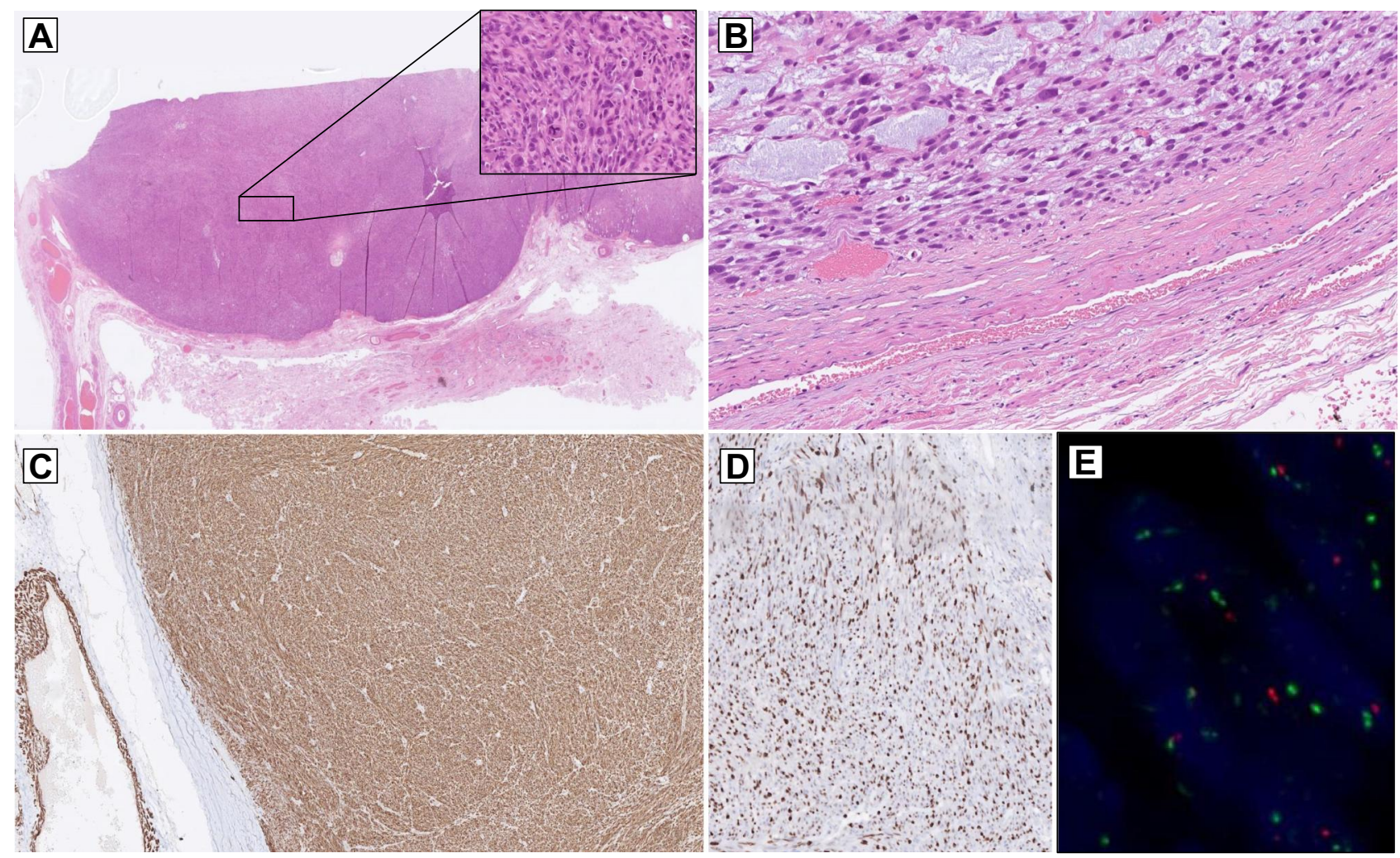

Figure 2 (A) Spindle cell sarcoma with subtotal substitution of testis parenchyma. On higher power, severe cytological atypia and pleomorphism, with frequent mitotic figures including atypical forms (inset). (B) Some areas of the tumor with microcystic spaces lined by atypical myogenic cells. Note the tight connection with tunica vaginalis. (C) The tumor comprises fascicles of atypical spindle cells with a strong immunopositivity for Desmin, and (D) high proliferative index ki67. (E) The assessment of MDM2 gene amplification by fluorescence in situ hybridization (FISH) resulted negative.

tumors has not yet been identified. In terms of frequency, paratesticular LMS originates from the spermatic cord, the scrotal structures (tunica, dartos muscle and scrotal subcutis) or the epididymis. ${ }^{7}$

Hematogenous metastases of LMS are primarily pulmonary or hepatic. ${ }^{8}$

Paratesticular LMS is difficult to diagnose preoperatively and a definitive diagnosis requires a histological confirmation; moreover, due to the rapid progression of this type of sarcoma, early recognition is critical for prognosis and for targeting a prompt histo-tailored therapy. ${ }^{9}$

During the course of 2020, emergency room visits across the country have dropped sharply since the pandemic took hold and substantial increases in the number of avoidable cancer deaths are to be expected as a result of diagnostic delays. ${ }^{10}$ Many institutions worldwide have also reported an increased number of cases that were diagnosed with more advanced cancers or in more severe clinical conditions. Some of these patients shared a significant diagnostic delay as a result of their reluctance to seek medical attention, seen as a potential risk factor for COVID-19 contagion, but also for the triage by the
American Society of Clinical Oncology which recommended that "any clinic visits that can be postponed without risk to the patient should be postponed."11

Literature data are not clear on the impact of diagnostic interval on patient outcome in soft tissue sarcoma. Due to heterogeneity and rarity of the disease, and the presence of more than 70 subtypes with different clinical behaviours, assessment of the time between first symptoms and histological diagnosis of sarcomas is challenging. However, it might be predicted that for high-grade sarcomas the longer the tumor is left untreated, the more likely it is to have metastasized, resulting in worse survival outcomes, while soft tissue tumors with indolent behaviour might have a longer interval and improved survival. ${ }^{12}$

Notably, it is well known that centralized sarcoma care may improve diagnostic interval and patient management, decreasing tumor size and staging at diagnosis.

In this case, given the presence of progressive scrotal mass enlargement and voluminous pulmonary lesions, diagnosis could have been anticipated had the patient presented for urological examination sooner. 


\section{Conclusion}

We reported the case of a patient with high-grade leiomyosarcoma who avoided any medical evaluation because of the COVID-19 pandemic. Such fear has become increasingly common in our Country, translating to lower rates of routine disease management and lower rates of hospitalizations for acute conditions, as well as severe conditions, such as cancer.

These patients incur the risk of increased morbidity, with potential severe complications and higher rates of mortality.

Whether or not a timely diagnosis could have changed the prognosis in this patient, given the aggressiveness of the disease, remains yet unknown.

\section{Ethics Approval and Informed Consent}

All procedures performed in this report involving human participants were in accordance with the ethical standards of the institutional and/or national research committee and with the 1964 Helsinki declaration and its later amendments or comparable ethical standards.

Written informed consent has been provided by the patient to have the case details and any accompanying images published. It was approved by Humanitas Clinical and Research Center Ethics Committee.

\section{Author Contributions}

All authors made a significant contribution to the work reported, whether that is in the conception, study design, execution, acquisition of data, analysis and interpretation, or in all these areas; took part in drafting, revising or critically reviewing the article; gave final approval of the version to be published; have agreed on the journal to which the article has been submitted; and agree to be accountable for all aspects of the work.

\section{Disclosure}

All of the authors declare that there are no potential conflicts of interest.

\section{References}

1. Khoubehi B, Mishra V, Ali M, Motiwala H, Karim O. Adult paratesticular tumours. BJU Int. 2002;90:707-715. doi:10.1046/j.1464410X.2002.02992.x

2. Dangle P, Basavaraj DR, Bhattarai S, Paul AB, Biyani CS. Leiomyosarcoma of the spermatic cord: case report and literature review. Can Urol Assoc J. 2007;1:55-58.

3. von Mehren M, Kane JM, Bui MM. NCCN guidelines insights: soft tissue sarcoma, version 1.2021. J Natl Compr Canc Netw. 2020;18 (12):1604-1612. doi:10.6004/jnccn.2020.0058

4. Casali PG, Abecassis N, Aro HT, et al. Soft tissue and visceral sarcomas: ESMO-EURACAN clinical practice guidelines for diagnosis, treatment and follow-up. Ann Oncol. 2018;29(Suppl 4):iv51iv67. doi:10.1093/annonc/mdy096

5. Dotan ZA, Tal R, Golijanin D, et al. Adult genitourinary sarcoma: the 25-year Memorial Sloan-Kettering experience. J Urol. 2006;176 (5):2033-2039. doi:10.1016/j.juro.2006.07.021

6. Alfarelos J, Gomes G, Campos F, et al. Paratesticular leiomyosarcoma: a case report and review of the literature. Urol Case Rep. 2017;11:30-32. doi:10.1016/j.eucr.2016.11.006

7. Moch H, Cubilla AL, Humphrey PA, Reuter VE, Ulbright TM. The 2016 WHO classification of tumours of the urinary system and male genital organs-part a: renal, penile, and testicular tumours. Eur Urol. 2016;70(1):93-105. doi:10.1016/j.eururo.2016.02.029

8. Ap Dafydd D, Messiou C, Thway K, Strauss DC, Nicol DL, Moskovic E. Paratesticular sarcoma: typical presentation, imaging features, and clinical challenges. Urology. 2017;100:163-168. doi:10.1016/j.urology.2016.09.005

9. Keenan RA, Nic an Riogh AU, Stroiescu A, et al. Paratesticular sarcomas: a case series and literature review. Ther Adv Urol. 2019;11:1756287218818029. doi:10.1177/1756287218818029

10. Tachibana I, Ferguson EL, Mahenthiran A, et al. Delaying cancer cases in urology during COVID-19: review of the literature. J Urol. 2020;204(5):926-933. doi:10.1097/JU.0000000000001288

11. American Society of Clinical Oncology. Patient care information. Available from: https://www.asco.org/asco-coronavirus-information /care-individuals-cancer-during-covid-19. Accessed January 7, 2021.

12. Soomers V, Husson O, Young R, Desar I, Van der Graaf W. The sarcoma diagnostic interval: a systematic review on length, contributing factors and patient outcomes. ESMO Open. 2020;5(1):e000592. doi:10.1136/esmoopen-2019-000592
Research and Reports in Urology

\section{Publish your work in this journal}

Research and Reports in Urology is an international, peer-reviewed, open access journal publishing original research, reports, editorials, reviews and commentaries on all aspects of adult and pediatric urology in the clinic and laboratory including the following topics: Pathology, pathophysiology of urological disease; Investigation and treatment of urological disease; Pharmacology of drugs used for the treatment of urological disease. The manuscript management system is completely online and includes a very quick and fair peer-review system, which is all easy to use. Visit http://www.dovepress.com/ testimonials.php to read real quotes from published authors. 